\title{
Navier-Stokes analysis of lift-enhancing tabs on multi-element airfoils
}

\author{
Paul G. Carrannanto ${ }^{\text {a }}$, Bruce L. Storms ${ }^{\text {b }}$, James C. Ross ${ }^{\mathrm{c}}$, Russell M. Cummings ${ }^{\mathrm{d}}$
}

${ }^{\mathrm{a}}$ Ford Motor Company, Dearborn, MI 48121, USA

b Aerospace Computing, Inc., Moffett Field, CA 94035, USA

${ }^{\mathrm{c}}$ NASA Ames Research Center, Moffett Field, CA 94035, USA

${ }^{\mathrm{d}}$ California Polytechnic State University, San Luis Obispo, CA 93407, USA

\begin{abstract}
The flow over multi-element airfoils with flat-plate lift-enhancing tabs was numerically investigated. Tabs ranging in height from 0.25 to $1.25 \%$ of the reference airfoil chord were studied near the trailing edge of the main element. The two-dimensional numerical simulation employed an incompressible Navier-Stokes solver using a structured, embedded grid topology. The effects of various tabs were studied at a constant Reynolds number on a two-element airfoil with a slotted flap. Both computed and measured results indicated that a tab in the main-element cove improved the maximum lift and lift-to-drag ratio relative to the baseline airfoil without a tab. Computed streamlines revealed that the additional turning caused by the tab may reduce the amount of separated flow on the flap. A three-element airfoil was also studied over a range of Reynolds numbers, with computed results shown to be in good agreement with experimental data.
\end{abstract}

\section{Nomenclature}

$c \quad$ reference airfoil chord

$C_{d} \quad$ section drag coefficient $\left(\equiv d / q_{\infty} c\right)$

$C_{l} \quad$ section lift coefficient $\left(\equiv l / q_{\infty} c\right)$

$C_{p} \quad$ pressure coefficient $\left(\equiv\left(p-p_{\infty}\right) / q_{\infty}\right)$

$d \quad$ section drag

$h$ tab height

$l \quad$ section lift

$L / D$ lift-to-drag ratio $\left(=C_{l} / C_{d}\right)$

$M \quad$ Mach number

$q \quad$ dynamic pressure $\left(=\frac{1}{2} \rho V^{2}\right)$

$\operatorname{Re}_{c} \quad$ Reynolds number, based on chord $\left(\equiv \rho_{\infty} V_{\infty} c / \mu_{\infty}\right)$

$V \quad$ velocity

$\alpha \quad$ angle of attack

$\delta \quad$ control surface deflection angle

$\mu \quad$ dynamic viscosity

$\rho \quad$ air density

Subscripts

f flap

$\max$ maximum

$\mathrm{s}$ slat

$\infty$ freestream condition 


\section{Introduction}

High-lift aerodynamics continues to play an important role in the design of new aircraft. Improved high-lift performance can lead to increased range and payload, or decreased landing speed and field length requirements. Hence, there is a continuous need to improve the maximum lift and lift-to-drag ratio, $L / D$, of the high-lift system. Much of the optimization work is performed in two-dimensional wind tunnel studies of multi-element airfoils. Even in two dimensions, however, the effects of Reynolds and Mach numbers can be significant, making it difficult to predict the full-scale aircraft performance at maximum lift conditions [1-3]. Reliable computational methods could help reduce the amount of required wind tunnel testing, while providing some insight into the complex flow physics of the multi-element airfoil systems.

This numerical investigation studies the performance of multi-element airfoil systems employing lift-enhancing tabs. A lift-enhancing tab is a small flat plate, on the order of $1 \%$ of the airfoil chord in height, mounted perpendicular to the pressure side near the trailing edge of an airfoil. The tab resembles a Gurney flap, which is a flat plate device fixed at the trailing edge of the aft-most element on a race car wing, and is used for increasing the wing's down force (see Fig. 1). As Liebeck first hypothesized, a Gurney flap increases the lift by deflecting the flow angle at the trailing edge of the airfoil [4]. The distinguishing features of a lift-enhancing tab are that it is retractable and is mounted slightly inboard from the trailing edge for structural purposes (see Fig. 2). For aircraft application, a tab can be deployed near the trailing edge of any airfoil element for high lift, or remain stowed during cruise.

Lift-enhancing tabs were tested near the trailing edge of the main element on a two-element airfoil, as shown in Fig. 2 [5]. Wind tunnel measurements showed that the tab increased the loading on the main element and delayed flow separation on the flap, which significantly increased the maximum lift coefficient, $C_{l_{\max }}$ and lift-to-drag ratio generated by the airfoil. A variety of tab arrangements were tested, and the highest performance was achieved with a tab height of $0.5 \%$-chord, which was somewhat different than the results of other Gurney flap studies [6-9]. In those studies, maximum lift generally increased with Gurney flap height, while $L / D$ decreased for flap heights larger than approximately $2 \%$-chord. With lift-enhancing tabs, however, maximum lift and $L / D$ were both nearly optimum for the same tab height.

The current work is based upon previous numerical investigations on conventional multielement airfoils $[10,11]$ and a numerical investigation of a single-element airfoil with a Gurney flap

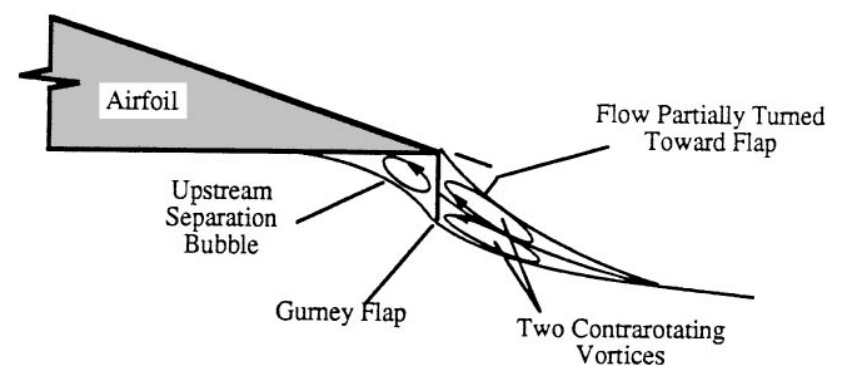

Fig. 1. Hypothesized trailing-edge flow conditions for an airfoil with a Gurney flap (adapted from Ref. [4]). 


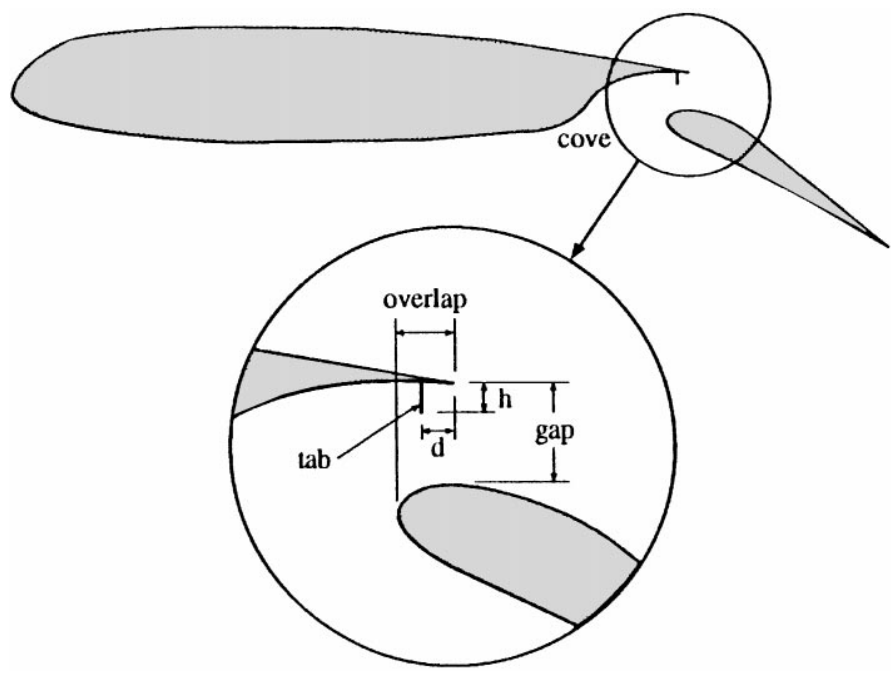

Fig. 2. Lift-enhancing tab geometry in main-element cove on two-element airfoil.
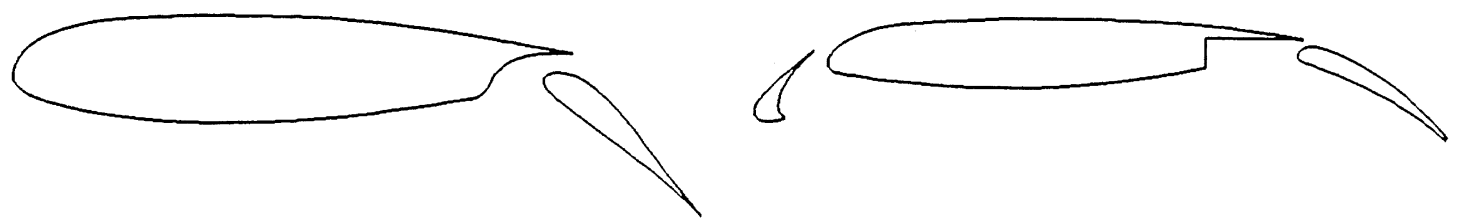

NACA 632-215 modB airfoil

Douglas landing configuration

- $\delta_{r}=43.5^{\circ}$, gap $=3.1 \% \mathrm{c}$, overlap $=4.2 \% \mathrm{c}$

- Baseline airfoil, measured $\mathrm{C}_{\max }=2.75, \mathrm{~L} / \mathrm{D}_{\max }=25$

- Large lift increment with $.5 \% \mathrm{c}$ tab in cove

- $\Delta \mathrm{C}_{\max }=11 \%, \Delta \mathrm{L} / \mathrm{D}_{\max }=48 \%$

- Compute experimental tab configurations, $\mathrm{Re}=3.7$ million

(a)

- Experimentally optimized at $\mathrm{Re}=9$ million, $\mathrm{M}=0.2$

- $30^{\circ}$ slat, $30^{\circ}$ flap, flap gap $=1.32 \%$, overlap $=1 \%$

- Reduction in $\mathrm{Cl}_{\max } \sim 0.1(2 \%)$ at $\mathrm{Re}=5$ or 16 million

- Increase flap gap and compute with tab in cove

- Re-optimize with tab at $\mathrm{Re}=16$ million

(b)

Fig. 3. Multi-element airfoil geometries: (a) baseline two-element airfoil [5]; (b) baseline three-element airfoil [1].

[12]. The former research, using an incompressible Navier-Stokes solver [13] and a Chimera grid scheme [14], has shown significant progress in the prediction of flow over multi-element airfoils and wings in high-lift take-off and landing configurations. Specifically, the lift behavior of twodimensional multi-element airfoils at various angles-of-attack up to stall has been accurately predicted with the INS2D-UP code [15]. The latter research applied the INS2D-UP code to investigate the effect of a Gurney flap on a NACA 4412 airfoil. That study revealed the local flow physics of the Gurney flap and also predicted accurate trends for the incremental lift and drag forces on the airfoil [12].

In the current research, the same numerical method is applied to study lift-enhancing tabs on two-dimensional multi-element airfoils. The first part of the analysis considers a two-element airfoil in a landing configuration with separated flow on the flap at $\mathrm{Re}_{c}=3.7 \times 10^{6}$ (see Fig. 3a). 
A two-dimensional wind tunnel experiment [5] showed that a $0.5 \%$-chord tab in the cove delayed the separation, improving the maximum lift by up to $11 \%$ and $L / D$ by up to $48 \%$. This data was used to validate the current numerical approach for studying lift-enhancing tabs. Although the computed drag is slightly high, the computations predict accurate trends for the increase in lift at a given angle-of-attack, as well as the reduction in angle-of-attack for maximum lift. Next, a three-element transport airfoil with slotted leading- and trailing-edge flaps is studied in a landing configuration, which was tested at $\mathrm{Re}_{c}=9.0 \times 10^{6}$ (see Fig. 3b) [1]. The experiment also showed that $C_{l_{\max }}$ was reduced by about $2 \%$ at Reynolds numbers of $\operatorname{Re}_{c}=5.0 \times 10^{6}$ and $\mathrm{Re}_{c}=16.0 \times 10^{6}$. The numerical investigation for that configuration tests the computational ability to predict the correct Reynolds number effects on maximum lift. At the same time, the analysis predicts that lift-enhancing tabs can be used to re-optimize the airfoil at the higher Reynolds number, while increasing the lift over the baseline airfoil.

\section{Numerical investigation}

\subsection{Flow solver}

The incompressible Navier-Stokes code, INS2D-UP [13,15], was selected for this analysis. Compressibility effects were neglected due to the low freestream Mach numbers $\left(M_{\infty}=0.2\right)$ for an aircraft in landing configuration. INS2D-UP employs the method of artificial compressibility to couple the pressure and velocity fields, and yields a hyperbolic set of partial differential equations which is solved with compressible flow algorithms. The convective fluxes are upwind-differenced using a third-order flux-difference splitting technique, while the viscous fluxes are central-differenced in standard second-order form. The resulting equations are solved with an implicit linerelaxation scheme, which provides high convergence rates for steady-state problems, and for sub-iterations in time-dependent problems. In this study, fully turbulent computations were performed using the one-equation Baldwin-Barth turbulence model [16].

\subsection{Geometry and boundary conditions}

A C-type structured grid was used with freestream conditions on the far-field boundaries. A grid sensitivity study verified that the effect of the freestream assumption was negligible for far-field radii greater than about 10 chords; the chosen outer far-field boundaries were ten chord lengths from the airfoil. The outflow boundary had a constant static pressure with extrapolated velocities. Simple averaging was used between the neighboring grid points along the wake cut. No-slip wall boundary conditions were applied at the airfoil surface.

\subsection{Grid generation and refinement}

The two-element airfoil and the grid are shown in Figs. 3a and 4, respectively. The grids used in this study were modeled after Rogers structured Chimera grids for multi-element airfoils $[13,15]$. The Chimera procedure utilizes an overlapping grid system to combine the different grids into a composite mesh. C-grids were generated individually for the main element and flap using the 


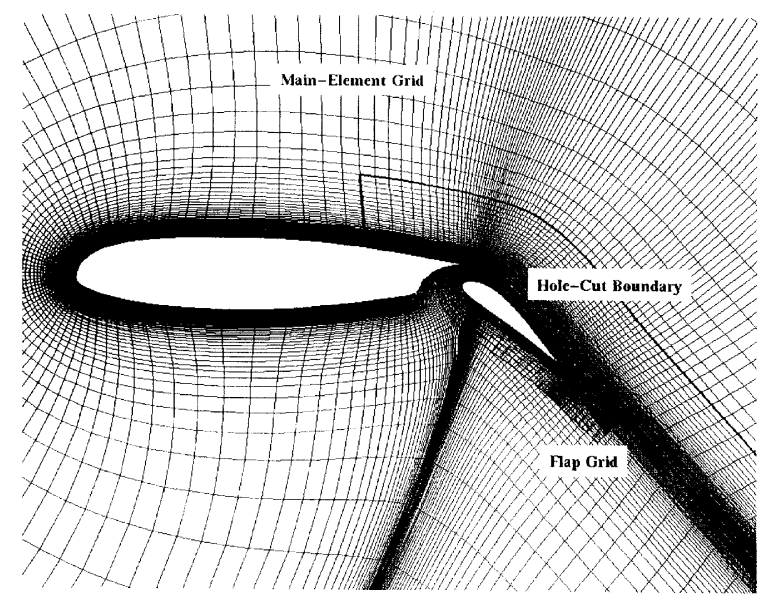

Fig. 4. Close-up of final two-element airfoil grid: grid dimensions are $307 \times 98$ for the main element and $155 \times 42$ for the flap.

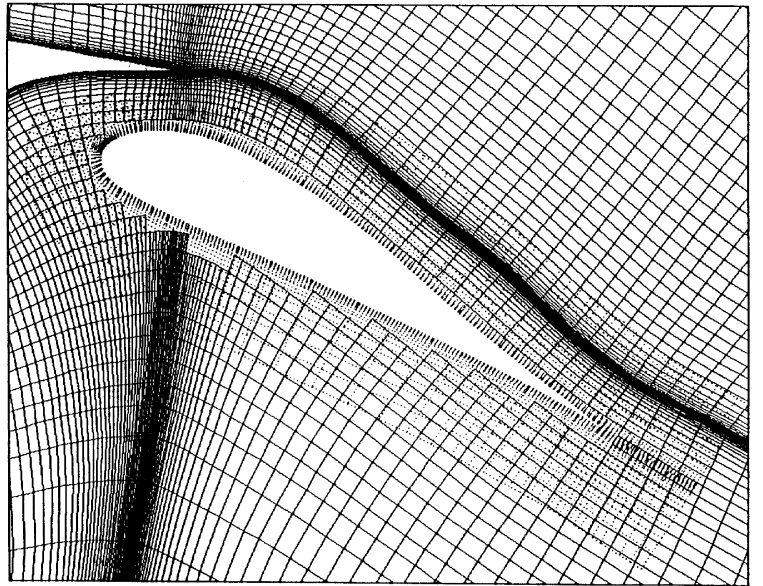

(a)

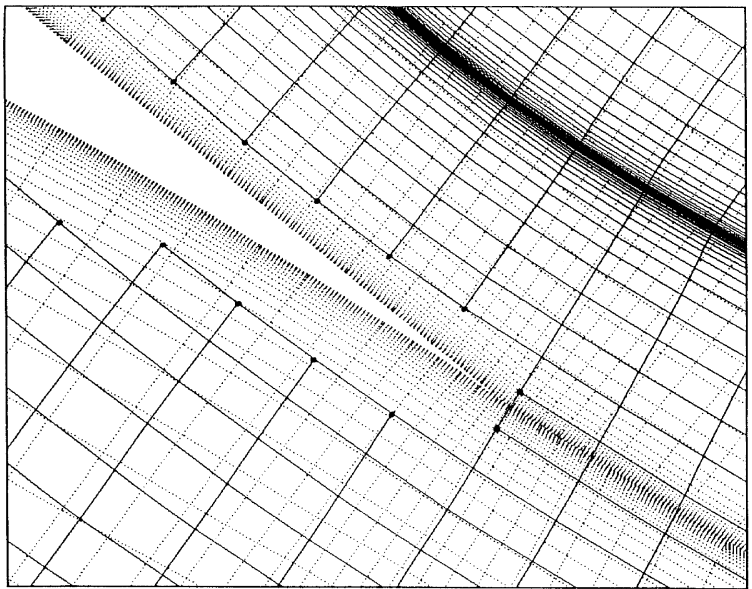

(b)

Fig. 5. Initial two-element airfoil grid; main-element grid (solid lines), flap grid (dashed lines). (a) Overlap region surrounding the flap. (b) Close-up of flap trailing edge; main-element fringe points are shown with larger dots.

HYPGEN code [17]. Grid points were clustered in the boundary layer, with a normal grid spacing at the wall of $10^{-5}$ chords $\left(y^{+} \approx 1\right)$ at the airfoil surface. The main element $\mathrm{C}$-grid was $307 \times 98$ (streamwise and normal directions, respectively) and the flap grid was $155 \times 42$.

The two grids were overlaid using the PEGSUS code [18]. In this technique, each C-grid is treated as a different zone, and holes are cut in each grid to accommodate the adjacent zonal boundaries. As shown in Fig. 5, the flap grid zone is embedded inside the main element, and the main element extends to the farfield boundary. In the composite mesh the grids are allowed to overlap, and numerical interpolation is used to transmit information across zonal boundaries. 


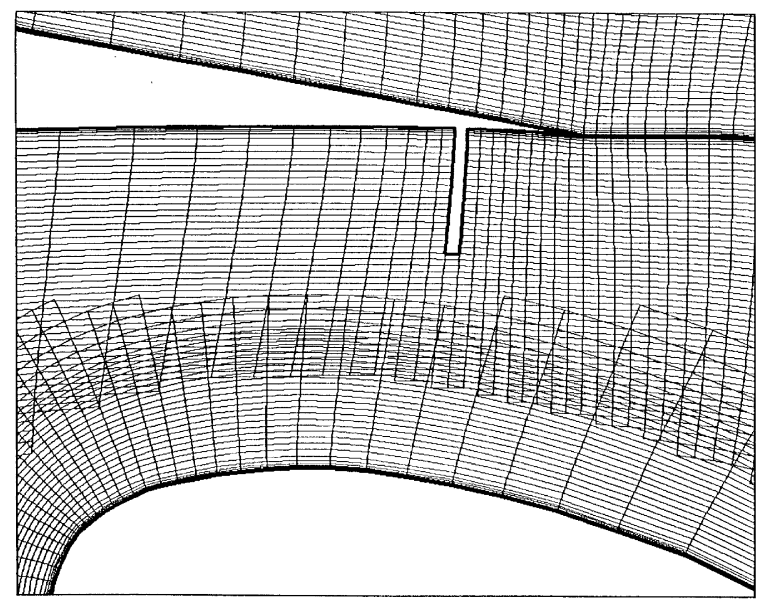

Fig. 6. Close-up of main-element cove showing grid resolution in the vicinity of the tab.

In order to model the lift-enhancing tabs, a no-slip wall boundary was created on the interior of the main element grid. This boundary condition was used to "blank out" grid points at the desired tab locations as shown in Fig. 6. This feature enabled a variety of tab heights and locations to be studied using the same main-element grid. Due to the small dimensions of a tab ( $h \approx 1 \%$-chord), grid points were clustered in the vicinity of the blanked-out points; the normal and streamwise spacings were 0.0005 and 0.001 chords, respectively. Computed streamlines revealed that this grid resolution was fine enough to resolve the dominant recirculating flow structures near the tab. Although it would be desirable to have a boundary layer resolution along the tab surfaces, this would significantly increase the overall grid dimensions, and further complicate the grid generation of varying sizes of tabs. Further details of the methods used to create and merge the multi-element airfoil grids may be found in Refs. [19,20].

\section{Results and discussion}

\subsection{Two-element airfoil}

The two-element airfoil geometry consists of a NACA $63_{2}-215$ Mod B airfoil with a 30\%-chord single-slotted flap, as shown in Fig. 3a [21]. The airfoil was tested at the NASA Ames Research Center $7 \times 10$-Foot Wind Tunnel \#2 [5]. The flap was deflected at $\delta_{f}=+43.5^{\circ}$ with a $3.1 \%$ chord gap and a $4.2 \%$-chord overlap. The wind tunnel model was mounted between false walls across the test section, and boundary layer control was used to minimize three-dimensional effects of the walls. Wind tunnel wall corrections were applied to the experimental data. The two-element airfoil without a tab was used as the baseline for comparison with the experimental data at a Reynolds number of $\mathrm{Re}_{c}=3.7 \times 10^{6}$.

Fig. 7 shows a comparison of the measured and computed pressure distributions for the airfoil at $\alpha \approx 8.5^{\circ}$. For the baseline airfoil results in Fig. $7 \mathrm{a}$, the computed pressures agree well with the 


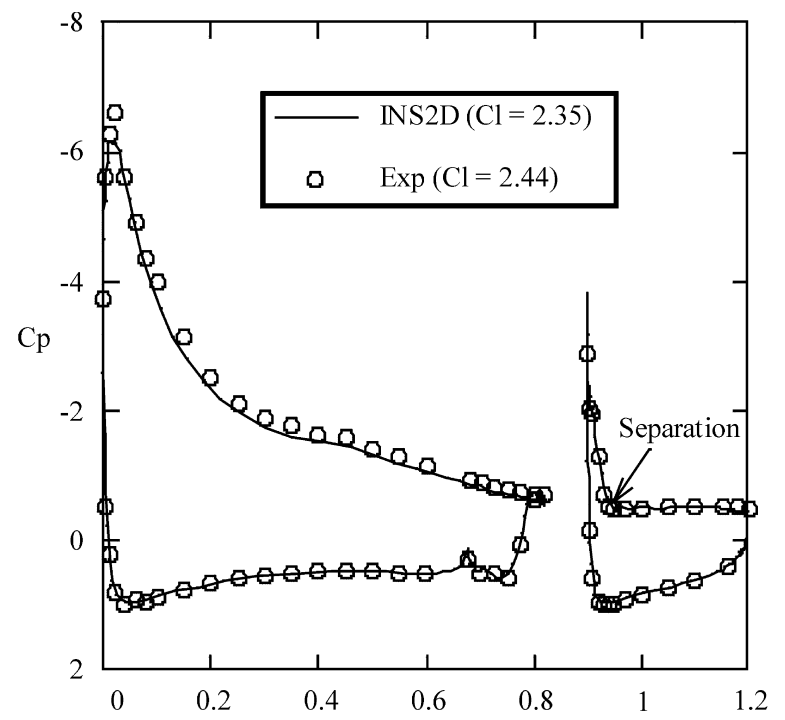

(a)

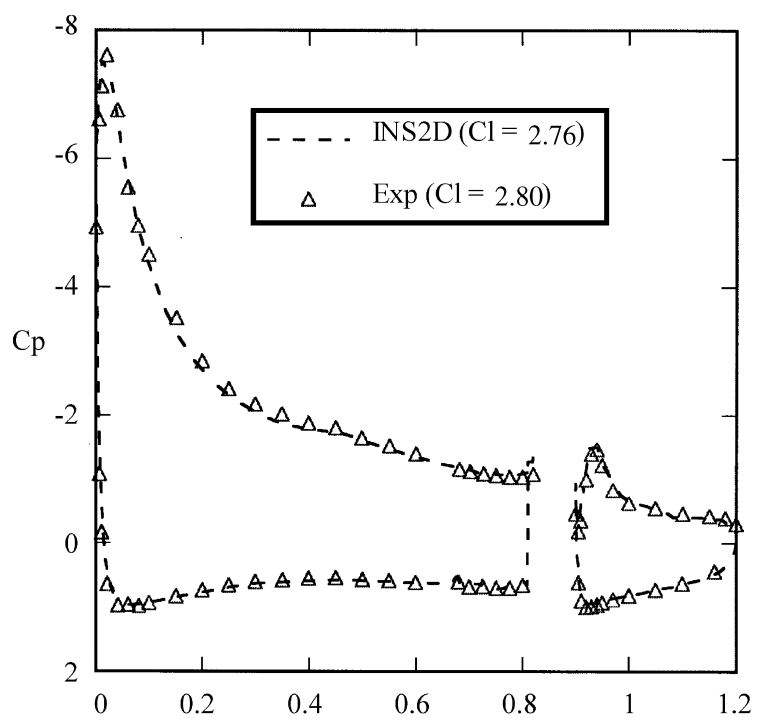

(b)

Fig. 7. Computed and measured pressure distributions for two-element airfoil; $\delta_{\mathrm{f}}=43.5^{\circ}, \quad$ gap $=3.1 \% c$, overlap $=4.2 \% c, \operatorname{Re}_{c}=3.7 \times 10^{6}$ : (a) baseline airfoil with no tab, $\alpha=8.43^{\circ}$; (b) airfoil with $1 \%-c$ tab located at $1 \%-c$ from trailing edge, $\alpha=8.5^{\circ}$.

measured data, except for slightly under-predicting the suction on the upper surface of the main element. The calculations also did an excellent job of predicting the separation point on the flap, which occurs at approximately $10 \%$ of the flap chord. The discrepancy between the measured and computed lift coefficient for this was case was less than $3.9 \%$.

The results for the airfoil with a $1 \%$-chord tab located at $1 \%$-chord from the main element trailing edge are shown in Fig. 7b. Excellent agreement between the computed and measured pressure is seen on the main element and flap. The discrepancy in lift coefficient for this case is less than $1.5 \%$. The $1 \%$-chord tab significantly increases the loading on the main element relative to the baseline airfoil, particularly near the trailing edge. The tab also suppresses the large suction peak near the leading edge of the flap; the lower suction peak weakens the adverse pressure gradient and allows the boundary layer to remain attached along the entire length of the flap. The overall effect of the tab in the computed case is a $17 \%$ increase in lift coefficient relative to the baseline airfoil, compared with a $15 \%$ increase in the experiment.

Simulated particle traces show the computed streamlines over the airfoil with and without the 1\%-chord flap, as see in Fig. 8. Fig. 8a shows a close-up of the slotted flap on the baseline airfoil. The flow exits the slot parallel to the main element trailing edge and minimal turning takes place as the flow separates at about $10 \%$ of the flap chord. However, when the tab is placed in the main element cove (see Fig. 8b), the streamlines are turned downward approximately $10^{\circ}$ at the main-element trailing edge. This turning reduces the effective angle of attack of the flap, which weakens the adverse pressure gradient and causes the boundary layer to reattach along the entire length of the flap. This effect is similar to adding camber to the trailing edge of the main element. Immediately downstream of the tab a recirculation region can be seen which resembles Liebeck's 


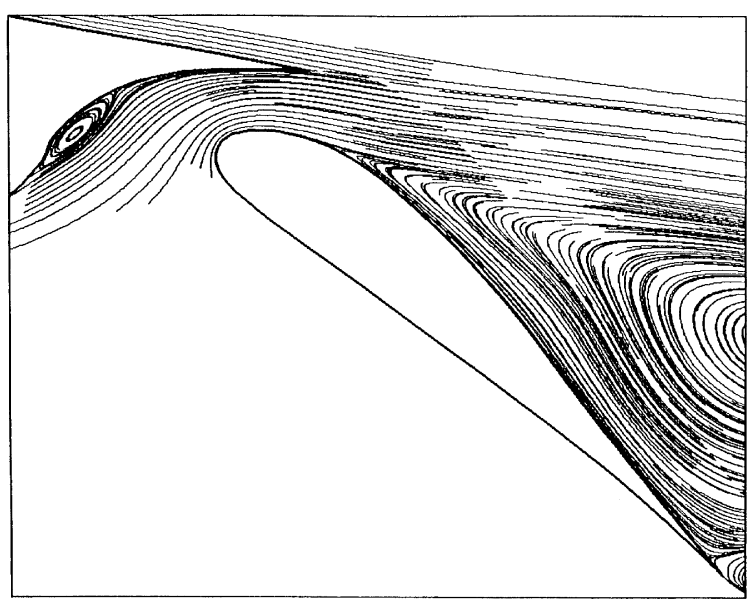

(a)

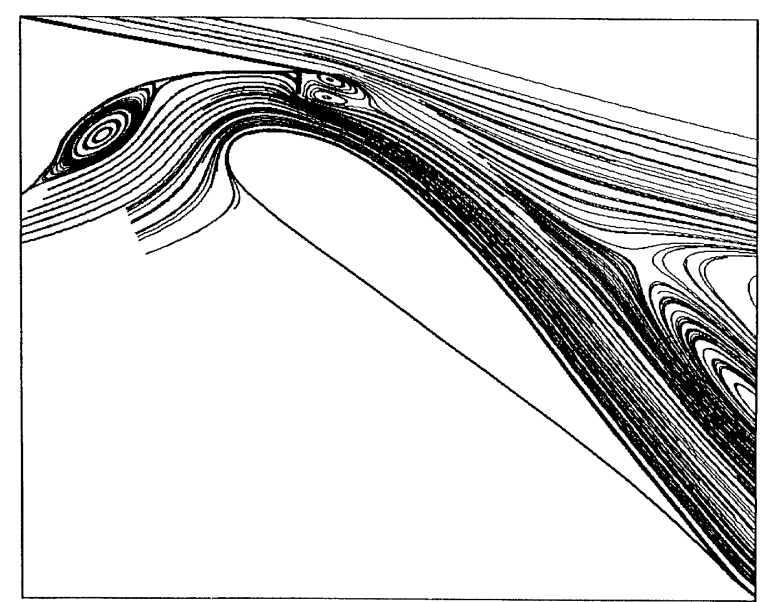

(b)

Fig. 8. Computed streamlines near flap for two-element airfoil; $\delta_{\mathrm{f}}=43.5^{\circ}$, gap $=3.1 \% c$, overlap $=4.2 \% c$, $\operatorname{Re}_{c}=3.7 \times 10^{6}$ : (a) baseline airfoil with no tab, $\alpha=8.43^{\circ}$; (b) airfoil with $1 \%-c$ tab located at $1 \%-c$ from trailing edge, $\alpha=8.5^{\circ}$.

hypothesized flowfield for a Gurney flap (see Fig. 1) [4]. Further downstream, the wake from the main element thickens and reverses direction as it encounters the adverse pressure above the flap. Rogers showed a similar off-surface separation in a computation for a three-element airfoil without tabs [11]. Even with the off-surface separation, the tab increases the overall lift of the geometry.

The measured and computed lift and drag coefficient curves for the airfoil with and without the tab are shown in Fig. 9. The lift curves are in good agreement at low angles of attack, as can be seen in Fig. 9a, where the lift curve is shifted by about $3^{\circ}$ due to the tab. However, the slopes of the computed lift curves are slightly lower than the experimental values. In addition, the computed maximum lift values and stall angles are higher than measured. This may be a result of the turbulence model and the lack of transition modeling in the fully turbulent computations [11]. However, the computations do reflect the correct qualitative changes due to the tab: the computations show a $5.2 \%$ increase in maximum lift due to the tab, which is close to the measured value of $3.9 \%$. The computations also match the measured results for the $3^{\circ}$ reduction in angle of attack at maximum lift due to the tab.

The measured and computed drag polars are compared in Fig. 9b. The agreement is good at low lift coefficients for the airfoil with and without the tab. As the lift coefficient increases, however, the computations predict higher drag values than were measured. The measured maximum lift-to-drag ratio was increased by $13 \%$ due to the tabs, compared with a computed increase of only $4.6 \%$. However, the computations were accurate in showing that the tab reduced the drag at moderate lift coefficients. Although the exact values of the lift and drag coefficients were not matched, the computations do show the correct trends, which makes the computation a useful design tool.

Several more tab heights and locations were numerically investigated on the main element. A constant angle of attack of $\alpha=13^{\circ}$ was selected for this study, since this was approximately the maximum lift angle for the tab heights previously studied. These earlier computations indicated 

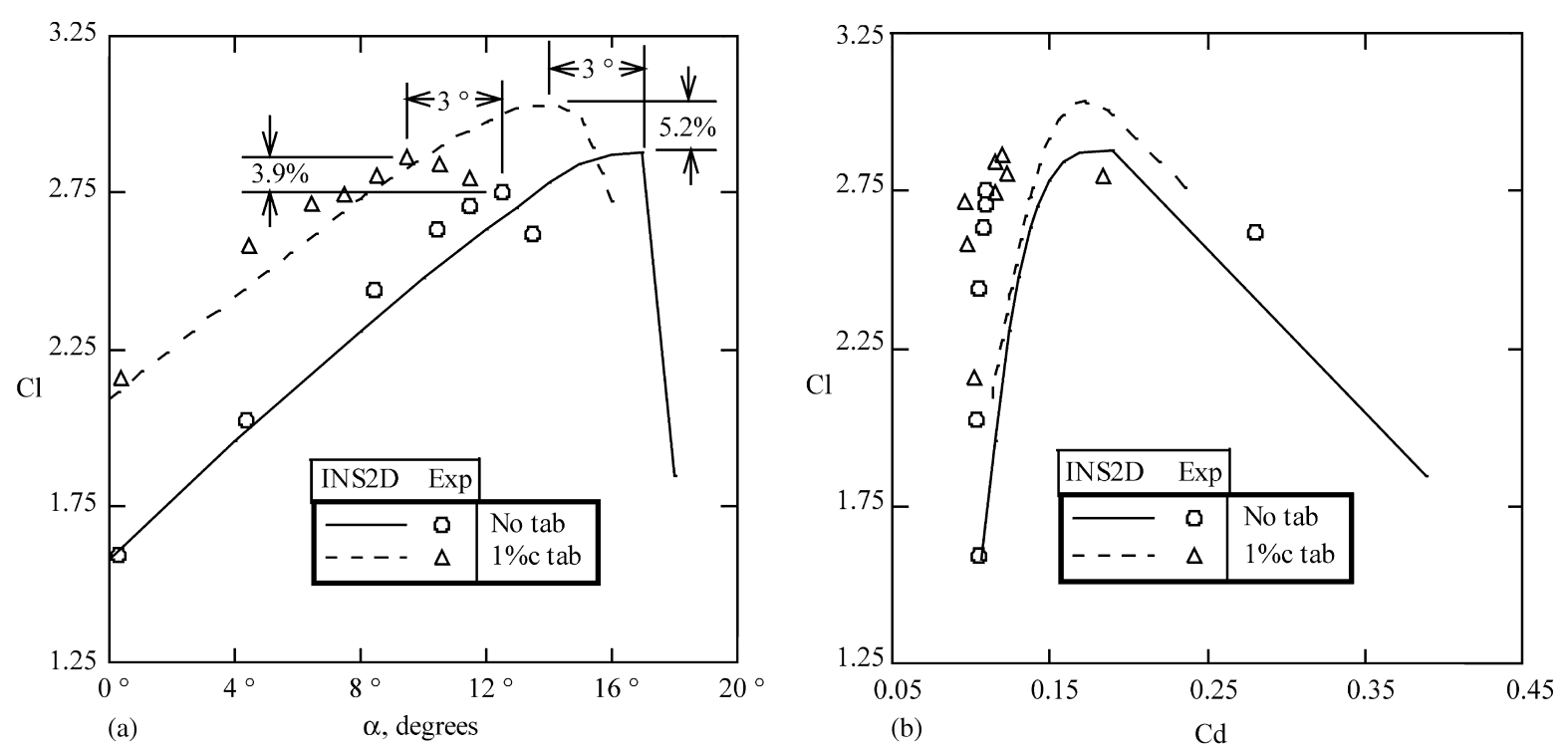

Fig. 9. Lift and drag of two-element airfoil with and without a $1 \% c$ tab; $\delta_{\mathrm{f}}=43.5^{\circ}$; gap $=3.1 \% c$, overlap $=4.2 \% c$, $\operatorname{Re}_{c}=3.7 \times 10^{6}$. (a) Lift coefficient versus angle of attack; (b) Lift coefficient versus drag coefficient.

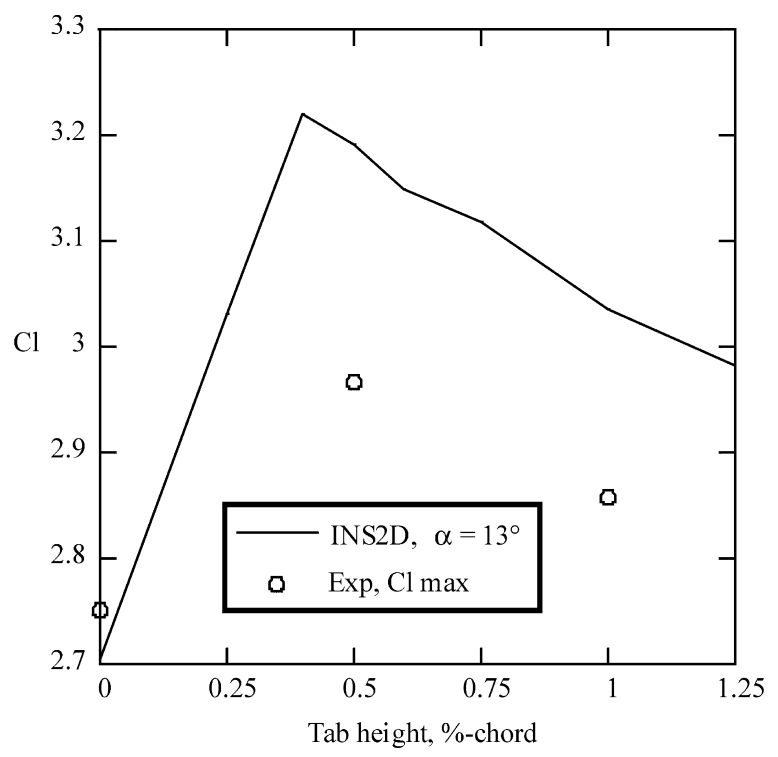

Fig. 10. Effect of tab height on lift; tab at main-element trailing edge on two-element airfoil; $\delta_{\mathrm{f}}=43.5^{\circ}$, gap $=3.1 \% c$, overlap $=4.2 \% c, \operatorname{Re}_{c}=3.7 \times 10^{6}$.

that the tabs performed best when placed at the trailing edge rather than slightly upstream, hence, all subsequent computations are performed with the tabs at the trailing edge. The computed and measured lift coefficient variation with tab height is presented in Fig. 10. The computations show that the optimum tab height is approximately $0.4 \%$-chord for this airfoil and flap rigging. This 
result is consistent with the experimental data, which showed that the maximum lift coefficient occurs for tab heights of approximately $0.5 \%$-chords.

\subsection{Three-element airfoil}

The three-element airfoil geometry is shown in Fig. 3b. This Douglas transport airfoil consists of a slat and a single-slotted flap. The two dimensional airfoil was tested at the Low-Turbulence Pressure Tunnel at NASA Langley Research Center [1]. Wind tunnel wall and boundary layer control corrections were applied to the data. The baseline airfoil (without tabs) was experimentally optimized for maximum lift at a Reynolds number of $\mathrm{Re}_{c}=9.0 \times 10^{6}$. The optimum settings for the slat were $\delta_{\mathrm{s}}=-30^{\circ}$, with a $2.95 \%$-chord gap and a $-2.5 \%$-chord overlap, while the optimum flap settings were $\delta_{\mathrm{f}}=+30^{\circ}$, with a $1.32 \%$-chord gap and a $1.0 \%$-chord overlap. The optimized airfoil geometry from the test was used as the baseline geometry for the current computations.

The computational grid for the three-element airfoil is shown in Fig. 11. This grid was originally developed by Rogers for a study of several turbulence models [11]. For the present study modifications were made to improve the grid resolution at the tab locations. The final grid has streamwise and normal dimensions of $121 \times 31,325 \times 100$, and $121 \times 41$ for the slat, main, and flap elements, respectively.

As a validation case the optimized configuration was computed at $\alpha=4^{\circ}$. Fig. 12 shows good agreement between the computed pressure distribution and measured data from Ref. [1]. Although the computed suction on the supper surface of the slat is slightly higher than measured, the discrepancy in total lift coefficient is less than 3.6\%. Fig. 13 shows how the maximum lift performance of a multi-element airfoil can vary significantly with Reynolds number, as was previously reported in Refs. [1-3]. The baseline airfoil flap rigging was optimized for $\mathrm{Re}_{c}=9.0 \times 10^{6}$, and the measured results show an approximately $2 \%$ reduction in maximum lift at both the lower and higher Reynolds numbers. A numerical prediction for the baseline airfoil was

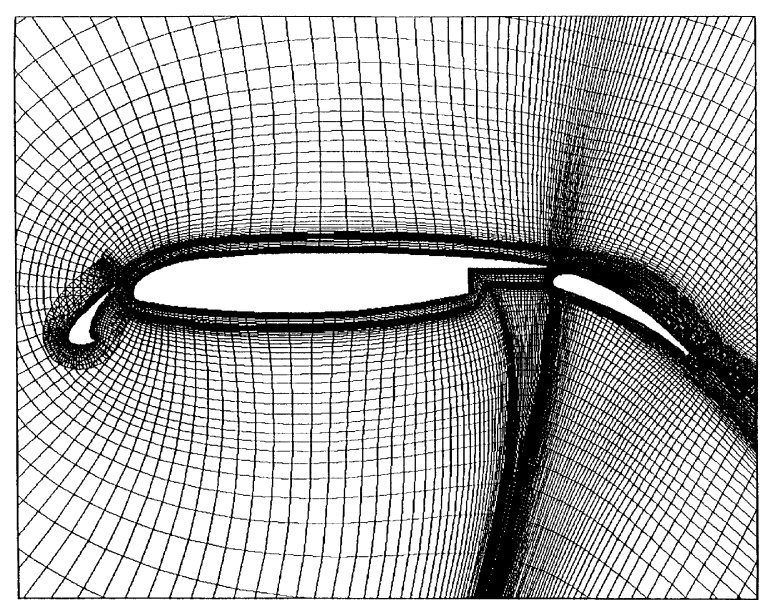

Fig. 11. Close-up three-element airfoil grid; grid dimensions are $121 \times 31,325 \times 100$, and $121 \times 41$, for the slat, mainelement, and flap, respectively. 


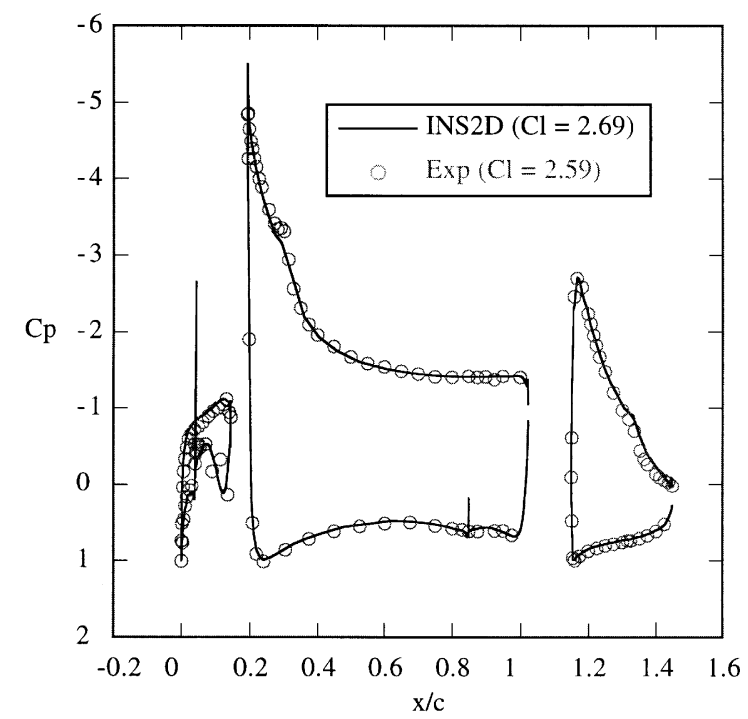

Fig. 12. Computed and measured pressure distributions for baseline three-element airfoil with a tab; optimized flap configuration; gap $=1.32 \% c, \alpha=4^{\circ}, \mathrm{Re}_{c}=9.0 \times 10^{6}$.

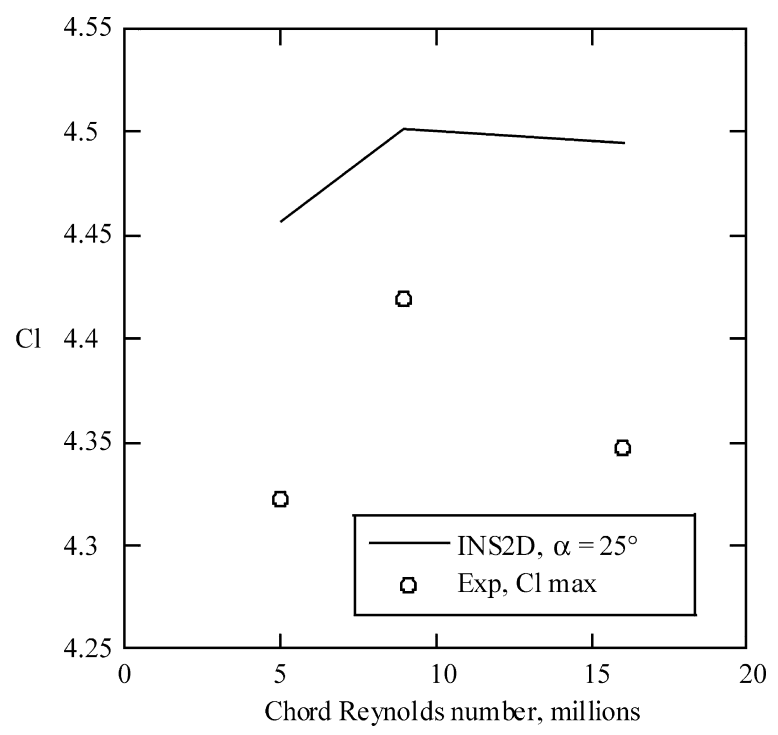

Fig. 13. Reynolds number effect of baseline three-element airfoil without a tab; optimized flap configuration; gap $=1.32 \% c$.

made at $\alpha=25^{\circ}$ (the approximate computed maximum lift angle) over the same Reynolds number range. Although the absolute values of the computed lift coefficients are higher than the measured data, the Reynolds number effects are similar, showing that the lift coefficient is highest at $\mathrm{Re}_{c}=9.0 \times 10^{6}$. All subsequent computations are for $\alpha=25^{\circ}$. 
The flap was moved from the optimum position in order to study the use of tabs for reoptimizing performance. The flap gap was increased from $1.32 \%$-chord to $2.18 \%$-chord, and the flap deflection was increased from $\delta_{\mathrm{f}}=30^{\circ}$ to $45^{\circ}$. The effect of an oversized gap is similar to increasing the Reynolds number with a fixed gap: maximum lift may decrease due to a reduction in favorable viscous interaction between the main element and the flap [3]. This can be a problem when a multi-element airfoil is optimized at a low Reynolds number and then tested under full scale conditions; the gap may be too large and no longer optimum at the higher Reynolds number. However, a tab changes the effective slot gap, making it possible to reoptimize the gap at the higher Reynolds number [5].

The airfoil was numerically investigated in the non-optimum flap setting at $\alpha=25^{\circ}$. The computed lift at two Reynolds numbers is shown in Fig. 14. For the airfoil without a tab, the flow on the flap is separated at both Reynolds numbers, which significantly reduces the lift performance relative to the optimum flap case. A further reduction in lift, $\Delta C_{l}=-0.17$, at the higher Reynolds number is seen, which is mostly like due to changes in the flow separation pattern.

In order to regain the lift performance for this non-optimum flap case, a tab is placed at the trailing edge of the main element. Since the optimum gap has been increased by almost $0.9 \%$ chord, tab heights ranging from $0.5 \%$-chord to $1 \%$-chord are considered. Unfortunately, the numerical solutions at $\alpha=25^{\circ}$ for $h>0.5 \%$-chord exhibited flow unsteadiness in the separation region. The $0.5 \%$-chord tab, seen in Fig. 14, significantly improved the lift coefficient relative to the non-optimum case without a tab; in fact, at $\mathrm{Re}_{c}=9.0 \times 10^{6}$ the lift was $4.9 \%$ higher than the optimum flap case without a tab. The large increase in lift is due to flow reattachment on the upper surface of the flap, as was also seen in the two-element airfoil. In addition, the $0.5 \%$-chord tab virtually eliminates the Reynolds number effects which were seen for the airfoil without

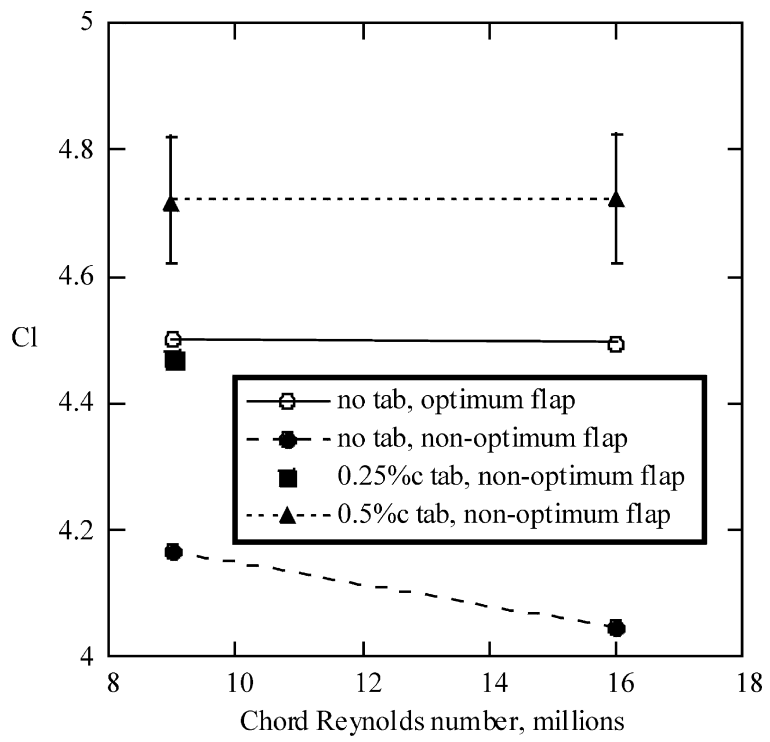

Fig. 14. Effect of tab height on lift for the three-element airfoil, $\alpha=25^{\circ}$; optimum flap configuration: $\delta_{\mathrm{f}}=30.0^{\circ}$, gap $=1.32 \% c$; non-optimum flap configuration: $\delta_{\mathrm{f}}=45.0^{\circ}$, Gap $=2.18 \% c$. 
a tab, which suggest that the tab may help to reduce some of the flow separation sensitivity on the flap.

In order to verify the above results, smaller tab heights are considered. The solution for a $0.25 \%$-chord tab at $R e_{c}=9.0 \times 10^{6}$ is also shown in Fig. 14 . The $0.25 \%$-chord tab also improves the lift to within $1 \%$ of the optimized flap case. This reaffirms that a tab may help to reoptimize the airfoil with the flap in a non-optimum position.

\section{Conclusions}

The effects of lift-enhancing tabs were numerically investigated on multi-element airfoil configurations. New grid refinement techniques were used to improve the accuracy of the solution near the overlapping grid boundaries. A two-element airfoil was investigated throughout a range of angles of attack. Although computations did not match the experimental magnitudes for maximum lift coefficient, the incremental impact of the tab was consistent with the data. Both computational and experimental results indicated that a $1 \%$-chord tab increased the loading on the main element and reattached the flow on the flap surface. Computed streamlines near the trailing edge revealed the additional flow turning caused by the tab. In addition, the optimal computed tab height of $0.4 \%$-chord was consistent with the available experimental data.

The computed trends for varying Reynolds number with the optimized three-element airfoil also matched the trends of the experimental data, although the computations once again did not match the measured values of $C_{l_{\max }}$. When the flap was positioned away from the optimum position, the flow over the flap separated, causing a significant reduction in lift relative to the optimum flap geometry. Although numerical solutions for larger tab heights showed evidence of flow unsteadiness, higher lift potential was observed. These results suggest that a tab may help to reoptimize an airfoil with the flap in a non-optimum position.

\section{Acknowledgements}

This research was supported by NASA Ames Research Center under Grant No. NCC 2-761. The authors would like to thank Dr. Stuart E. Rogers of NASA Ames for his assistance throughout this investigation.

\section{References}

[1] Valarezo WO, Dominik CJ, McGhee RJ. Reynolds and Mach number effects on multielement airfoils. Proceedings of the 5th Symposium on Numerical and Physical Aspects of Aerodynamic Flows, Long Beach, CA: California State University, January 1992.

[2] Mack MD, McMasters JH. High Reynolds number testing in support of transport airplane development. AIAA Paper 92-3982, 1992.

[3] Woodward DS, Hardy BC, Ashill PR. Some types of scale effects in low-speed high-lift flows. 16th International Congress of the Aeronautical Sciences Congress, 1988.

[4] Liebeck RH. Design of subsonic airfoils for high lift. Journal of Aircraft 1978; 15 (9): 547-61. 
[5] Ross JC, Storms BL, Carrannanto PC. Lift-enhancing tabs on multielement airfoils. Journal of Aircraft 1995; 32 (3): $649-55$.

[6] Katz J, Largman R. Effect of 90 degree flap on the aerodynamics of a two-element airfoil. Journal of Fluids Engineering 1989; 111 (March): 93-4.

[7] Katz J, Dykstra L. Study of an open-wheel racing-car's rear-wing aerodynamics. Society of Automotive Engineers TP 890600, February 1989.

[8] Storms BL, Jang CS. Lift enhancement of an airfoil using a Gurney flap and vortex generators. Journal of Aircraft 1994; 31 (3); 542-7.

[9] Storms BL, Ross JC. Experimental study of lift-enhancing tabs on a two-element airfoil. Journal of Aircraft 1995; 32 (5): $1072-8$.

[10] Rogers SE, Wiltberger NL, Kwak D. Efficient simulation of incompressible viscous flow over single and multielement airfoils. Journal of Aircraft 1993; 30 (5): 736-43.

[11] Rogers SE. Progress in high-lift aerodynamic calculations. Journal of Aircraft 1994; 31 (6): 1244-51.

[12] Jang CS, Ross JC, Cummings RM, Numerical investigation of an airfoil with a Gurney flap. Aircraft Design 1999; 1 (2) 78-88.

[13] Rogers SE, Kwak D. An upwind differencing scheme for the incompressible Navier-Stokes equations. Journal of [Applied Numerical Mathematics 1991; 8 (1): 43-64.

[14] Benek JA, Buning PG, Steger JL. A 3-D Chimera grid embedding technique. AIAA Paper 85-1523, July 1985.

[15] Rogers SE, Kwak D. Upwind differencing scheme for the time-accurate incompressible Navier-Stokes equations. AIAA Journal 1990; 28 (2): 253-62.

[16] Baldwin BS, Barth TJ. A one-equation turbulence transport model for high Reynolds number wall bounded flows. AIAA Paper 91-0160, January 1991.

[17] Chan WM, Steger JL. A generalized scheme for three-dimensional hyperbolic grid generation. AIAA Paper 91-1586, June 1991.

[18] Tramel TW, Suhs JL. PEGSUS 4.0 user's manual, Arnold Engineering Development Center TR-91-8. June 1991.

[19] Carrannanto PG, Storms BL, Ross JC, Cummings RM. Navier-Stokes analysis of lift-enhancing tabs on multielement airfoils. AIAA Paper 94-0050, January 1994.

[20] Carrannanto PG. Navier-Stokes analysis of lift-enhancing tabs on multi-element airfoils, MS Thesis, California Polytechnic State University, San Luis Obispo, CA, August 1993.

[21] Hicks RM, Schairer ET. Effects of upper surface modifications on the aerodynamic characteristics of the NACA $63_{2}$-215 airfoil section. NASA TM 78503, 1979. 